\title{
Have actual waiting times been reduced by introducing the DILO reform for cancer patients in Poland?
}

\author{
Karolina Osowiecka1, 2 , Monika Rucińska1, 3 , Sergiusz Nawrocki ${ }^{4}$
}

Introduction. Relative 5-year cancer survival rates in Poland are around 10\% lower than the average of the whole EU. One of the likely factors for poorer treatment outcomes in Poland may be the long times between when cancer is suspected to starting treatment. This study has thus aimed to determine whether the introduced oncology reforms have succeeded in reducing such times.

Materials and methods. The study survey was undertaken at 6 oncological centres on patient subjects before ( $n=1373)$ and after $(n=431)$ the oncological reform $(D I L O)$ had been introduced. Data was obtained from an inhouse devised questionnaire together with patient interview and their medical history. The following waiting times were estimated: A) from suspicion of cancer, (date of first doctor visit due to appearance of symptoms, screening/ /follow-up or prevention), to diagnosis (date of histopathological confirmation), B) from suspicion of cancer to the start of treatment and C) from diagnosis to starting treatment before and after the DILO reform had been introduced. Results. The median waiting time between suspicion of cancer and treatment was 11 weeks before the DILO reform but was not significantly shortened after its introduction; the reduction being barely 3 days. This waiting time was however increased by 8 days in those patients without DILO cards. Before the DILO reform, the median time from diagnosis was 5.9 weeks, but was reduced by 8 days in patients bearing the DILO card and indeed increased in those without the DILO card by over 2 weeks.

Conclusions. Cancer treatment waiting times in Poland is still somewhat long (over 9 weeks in most cases). Introducing the oncological reform has not significantly impacted on shortening the waiting times in cancer patients for receiving oncological treatment.

NOWOTWORY J Oncol 2017; 67, 3: 168-173

Key words: cancer, waiting time, diagnosis, health services, DILO reform

\section{Introduction}

Cancer constitutes a serious health problem in Poland and the world. At present it is the second commonest cause of mortality, whilst in women aged between 30 and 69 years it is the first [1]. Within the backdrop of the European Union (EU), Poland is a country with a relatively low cancer incidence but with a high mortality. This low incidence rate is likely because of incomplete reporting of new cancer diagnoses made to the National Tumour Registry (KRN) by healthcare providers. In terms of mortality rates, Poland occupies second from last place after Hungary. According to the latest analyses of EUROCARE 5, the five-year relative survival in Poland is around $10 \%$ lower than the EU average [2-4]. One likely reason for this may be a late detection

\footnotetext{
${ }^{1}$ Department of Radiation Oncology, Hospital of the Ministry of Internal Affairs with Warmia and Mazury Oncology Center Olsztyn, Poland

${ }^{2}$ Department of Public Health, University of Warmia and Mazury, Olsztyn, Poland

${ }^{3}$ Department of Oncology, University of Warmia and Mazury, Olsztyn, Poland

${ }^{4}$ Department of Oncology and Radiotherapy, Medical University of Silesia, Katowice, Poland
} 
of cancer in Poland; often already made at advanced stages. Another factor causing such worse outcomes in Poland, when compared to the EU, may be the low funding for medical services, resulting in reduced access to diagnostic and therapeutic services, thereby increasing the time for starting cancer treatment. Expenditure for cancer treatment per capita in Poland is about one third of the EU average (respectively 37 and 102 euros per annum). The ratio of mortality to morbidity is over 0.6 in Poland and it is one of the highest in the EU; as is also the case for Romania and Greece. In countries where funding for cancer treatment is higher, then this ratio becomes close to 0.4 [2]. The effectiveness of a given cancer therapy is most probably affected by waiting time as variously supported by published studies, although conclusions have not always been unequivocal. A Dutch study [5] found that prolonging waiting time of up to 3 months after a diagnosis of head and neck head cancer reduced 5 year overall survival by $18 \%$ and significantly increased mortality risk after 2 months from diagnosis. A meta-analyses showed similar findings [6], where prolonged waiting times for treatment from the first signs of breast cancer (<3 vs 3-6 months) reduced the 5-year survival by 5-7\%.

Our study aim was to determine whether the oncological reform introduced in Poland actually shortened the real waiting time for diagnoses and treatment in cancer patients.

\section{Materials and methods}

Study subjects were 1373 patients treated for cancer prior to the advent of the oncological cancer reform (22.05.2014 to 19.02.2015) and 431 cancer patients after the reform (from 17.11.2015 to 06.06.2016); at 6 cancer centres in Poland. Originally 11 cancer centres had been invited to participate, differing in geographic location, size, organisation and financing of their medical services. Six centres were approved for the study, three of which are regional oncological centres funded by the National Health Fund $(\mathrm{IA}-\mathrm{C})$ and the other 3 being privately funded; of the latter, one centre was funded by the National Health Fund (IIA) and two centres were owned by an investor who covers the costs of medical services (IIIA-B). The study was sponsored by the Oncology Foundation 2025.

An in-house questionnaire was developed for the survey and such data was supplemented by patient medical histories. The questionnaire had been previously validated by a twice repeated pilot study on 50 patients before and after 2 weeks. Reply concordance was tested by the Cohen kappa coefficient.

Our study received approval from the Bioethics Commission at the University of Warmia and Mazury in Olsztyn. All respondents agreed to participate in the study and have their medical records at our disposal.

The median waiting times were estimated as follows: A) from suspicion of cancer, (date of first doctor's visit due to the appearance of abnormal symptoms suggesting cancer or if they are discovered whenever screening/follow-up or prevention tests were undergone and confirmed by tests after referral), to diagnosis (date of histopathological confirmation), B) from suspicion of cancer to the start of treatment and $C$ ) from diagnosis to starting treatment before and after the DILO reform had been launched.

From the cancer suspicion time to treatment, $112 \mathrm{pa}-$ tients were excluded from the study whilst in addition, 474 patients were excluded from the study in the groups: waiting time from suspicion to diagnosis and waiting time from diagnosis to starting treatment (Fig. 1).

\section{Statistical analyses}

The distribution of variables was tested by the Shapiro-Wilk test. As aforementioned the questionnaire was validated using the Kappa Cohen Coefficient. Differences in subgroup ratios were tested using the $\chi^{2}$ test. The Mann-Whitney $U$ test was used for comparing waiting times before and after the oncological reform. Statistical significance was assumed to be $p<0.05$. Analyses were carried out using STATISTICA software (version 12.5) (StatSoft, Poland) and SPSS Statistics 23.0.

\section{Results}

There were 1266 and 426 patient subjects respectively in the study, (time from suspicion of cancer to starting treatment), before and after the Diagnostic and Treatment of Cancer (DILO) reform had been introduced. For the staging analysis, i.e. from suspicion of cancer to diagnosis and from diagnosis to treatment, there were respectively 890 and 328 patient subjects before and after the reform had been introduced; Figure 1 and Table I. Upon validating the questionnaire, the replies agreed very satisfactorily (kappa:0.81-1.00; $p<0.0001$ ) when the 'patient pathway' was started and for gender and age. Good agreement was seen (kappa: $0.61-0.80, p<0.0001$ ) when patients used private practice for diagnoses whilst moderate agreement was obtained (kappa: 0.41-0.60; $<<0.0001$ ) for the date at which cancer was suspected. The distribution of the waiting time was non-parametric $(p<0.001)$.

The median waiting time from suspicion of cancer to starting treatment was 11 weeks before the oncological cancer reform had been launched. After the reform, this time was not significantly reduced in patients possessing a DILO card; the difference being only 3 days, $p=0.43$. Nevertheless, in patients without a DILO card, the median waiting time between when cancer was suspected to treatment was longer by 8 days; $p=0.81$ (Fig. 2A). The median waiting time for histopathological diagnosis from when cancer was suspected was 5.9 weeks prior to the oncological cancer reform. Within this period, the median duration of histopathological testing, as measured from the date of sample collection until the 


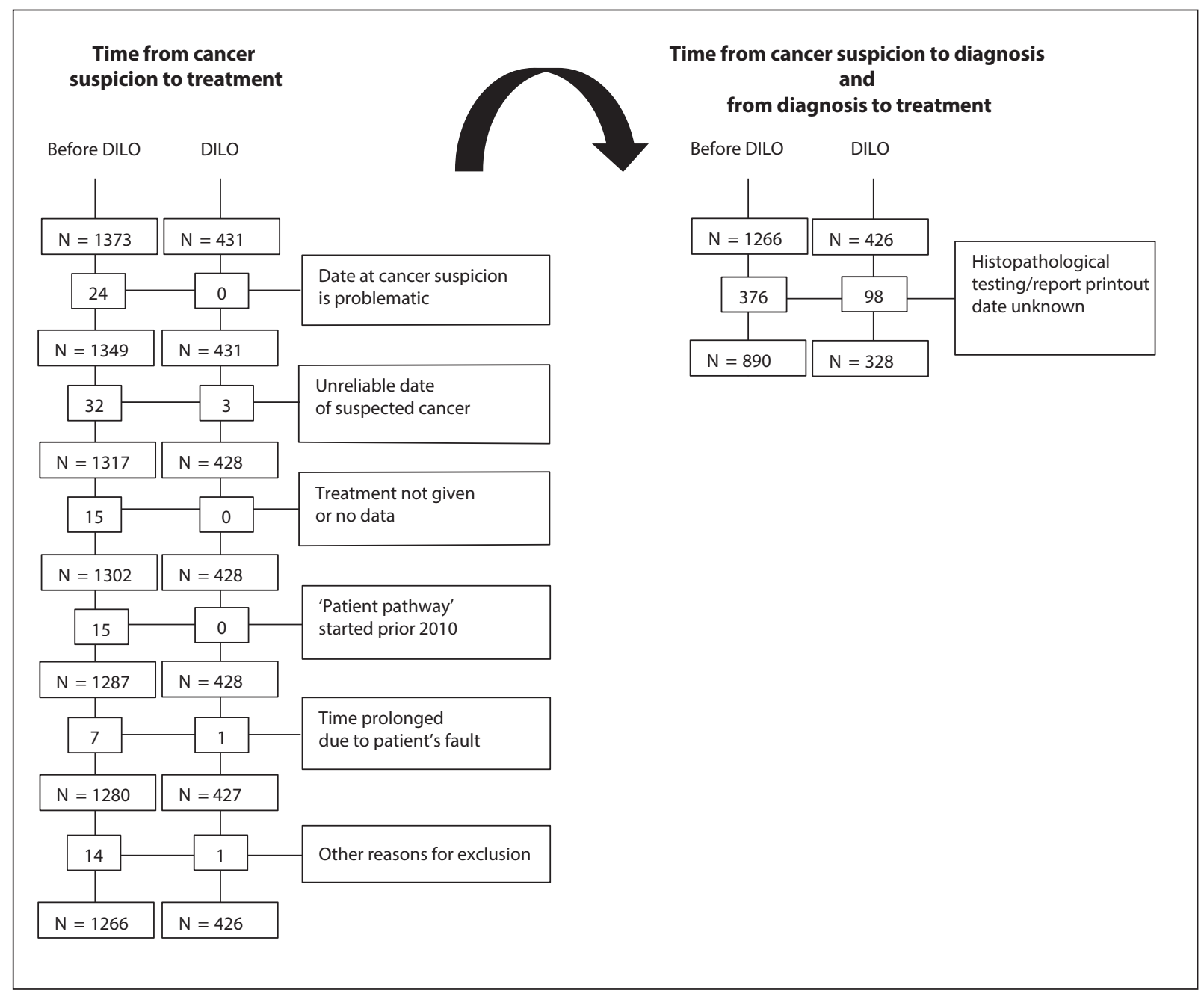

Figure 1. Study enrolment criteria for subject patients

results were officially reported, was 7 days. In those patients with a DILO card, the diagnosis time was shortened by 8 days $(p=0.01)$, whilst the duration of histopathological testing remained unchanged. Patients without DILO cards however had an increased diagnosis time by more than 2 weeks $(p=0.03)$ and their median time of histopathological testing also increased (by 2 days). The time from histopathological diagnosis to starting treatment had not substantially changed since the DILO reform was introduced (Fig. 2B).

\section{Discussion}

Guidelines and regulations in many countries are in place which govern patient waiting times for oncological treatment. In the UK, this time is legally guaranteed; the maximum waiting time between a GP (General Practitioner) visit to a specialist physician appointment is 14 days, whilst the duration between the diagnosis of cancer to treatment is 31 days. The maximum waiting time between a GP/family doctor referral when cancer is suspected until starting treatment is 62 days. Similarly in Denmark, the first visit to an oncologist must be made within 2 weeks upon whence a referral is issued, (referral to a specialist electronically provided, where the patient is also invited to visit by telephone or electronic means), whilst oncological treatment must begin no later than the ensuing 2 weeks. Waiting times for complementary chemotherapy or radiotherapy cannot be more than 4 weeks from the date that the referral was received. Very detailed recommendations are made for certain cancers, for example breast cancer, where the time from referral to imaging diagnostics and its completion cannot take more than 6 calendar days and that the diagnoses should be finished in the next 8 days, which includes histopathological findings. Oncological treatment must then begin no later than after another 13 days has elapsed; the total waiting time from when breast cancer is suspected to starting treatment is 27 days in this country. In Norway, the referral should reach a specialist and be considered within 5 working days, whilst treatment of at least $80 \%$ patients is expected to commence within 20 working days of the referral. In the Czech Republic, the maximum waiting time for computer tomography (CT) is 3 weeks, for magnetic resonance (MR) 5 weeks and 6 weeks for mammography [7]. 
Table I. Characteristics of patient subjects before and after introducing the DILO oncological reform

\begin{tabular}{|c|c|c|c|c|c|}
\hline \multirow{4}{*}{$\begin{array}{l}\text { Patient } \\
\text { characteristics }\end{array}$} & \multicolumn{4}{|c|}{ DILO reform } & \multirow[t]{4}{*}{$\chi^{2}$ test } \\
\hline & \multicolumn{2}{|c|}{ BEFORE } & \multicolumn{2}{|c|}{ AFTER } & \\
\hline & Number & $(\%)$ & Number & $(\%)$ & \\
\hline & 1266 & 100 & 426 & 100 & \\
\hline \multicolumn{6}{|l|}{ Age } \\
\hline$\leq 65$ lat & 870 & (69) & 253 & (59) & \multirow{2}{*}{$\mathrm{p}<0.001$} \\
\hline$>65$ lat & 396 & (31) & 173 & (41) & \\
\hline \multicolumn{6}{|l|}{ Gender } \\
\hline Women & 683 & (54) & 179 & (42) & \multirow{2}{*}{$p<0.001$} \\
\hline Men & 583 & (46) & 247 & (58) & \\
\hline \multicolumn{6}{|c|}{ Initial tumour localisation } \\
\hline Breast & 317 & $(25)$ & 64 & (15) & \\
\hline Lung & 224 & $(17)$ & 73 & (17) & \\
\hline Large intestine & 164 & $(13)$ & 60 & (14) & \\
\hline Prostate gland & 123 & $(10)$ & 69 & (16) & \\
\hline $\begin{array}{l}\text { Head and neck } \\
\text { regions }\end{array}$ & 123 & $(10)$ & 39 & (9) & $\mathrm{p}<0.001$ \\
\hline $\begin{array}{l}\text { Female } \\
\text { reproductive } \\
\text { organs }\end{array}$ & 119 & (9) & 34 & (8) & \\
\hline $\begin{array}{l}\text { Upper gastro- } \\
\text { intestinal tract }\end{array}$ & 60 & (5) & 27 & (7) & \\
\hline $\begin{array}{l}\text { Renal tract } \\
\text { (excluding } \\
\text { prostate) }\end{array}$ & 40 & (3) & 15 & (4) & \\
\hline Brain & 35 & (3) & 14 & (3) & \\
\hline Others & 61 & (5) & 31 & (7) & \\
\hline \multicolumn{6}{|c|}{ Reasons for starting the 'patient pathway' } \\
\hline $\begin{array}{l}\text { Feeling illness/ } \\
\text { /lesions noticed }\end{array}$ & 993 & (78) & 310 & (73) & \\
\hline $\begin{array}{l}\text { Screening/ } \\
\text { /prevention testing }\end{array}$ & 197 & (16) & 72 & (17) & $p=0.006$ \\
\hline $\begin{array}{l}\text { Follow-up testing } \\
\text { at cancer clinics }\end{array}$ & 76 & (6) & 44 & $(10)$ & \\
\hline \multicolumn{6}{|l|}{ Centre } \\
\hline IA & 386 & $(30)$ & 152 & (36) & \\
\hline IB & 267 & $(21)$ & 101 & (24) & \\
\hline IC & 149 & $(12)$ & 109 & (25) & $\mathrm{p}<0.001$ \\
\hline$\| \mathrm{A}$ & 207 & $(16)$ & 64 & (15) & \\
\hline IIIA & 134 & $(11)$ & 0 & $(0)$ & \\
\hline IIIB & 123 & $(10)$ & 0 & $(0)$ & \\
\hline \multicolumn{6}{|c|}{ Private sector health services } \\
\hline Yes & 281 & $(22)$ & 96 & (23) & \\
\hline No & 753 & $(60)$ & 330 & (77) & $p=0.066$ \\
\hline No data & 232 & $(18)$ & 0 & $(0)$ & \\
\hline \multicolumn{6}{|c|}{ Starting treatment methods } \\
\hline Surgery & 609 & $(48)$ & 175 & (41) & \\
\hline $\begin{array}{l}\text { Radiotherapy } \\
\text { and/or } \\
\text { chemotherapy }\end{array}$ & 604 & $(48)$ & 219 & (51) & $p=0.004$ \\
\hline Endocrine therapy & 53 & (4) & 32 & (8) & \\
\hline
\end{tabular}

Up until the 1st January 2015 in Poland, there had been no statutory maximum waiting time for oncological treatment. The reform introduced for rapid oncological diagnosis and treatment presupposes certain durations in which the various stages of diagnostics should occur. The statutory maximum time for initial diagnostics is 35 days (and 28 days from 2016) whilst the maximum time for in-depth diagnosis is 28 days. The time between consultation and starting treatment cannot exceed 14 days [8]. Nonetheless, the reform does not define the maximum time after a GP/ /family doctor referral, nor that of another specialist, between when cancer is suspected to when starting treatment. Most of the DILO card patients (56\%) received specialist outpatient care (Polish AOS) after cancer had been diagnosed, but only $14 \%$ of DILO card patients DILO remained under primary healthcare physicians (Polish POZ). Unfortunately the NFZ data on how the DILO reform is performing is as yet incomplete and they do not reflect the real situation of waiting time for the diagnosis and treatment of cancer. This presented study has determined the actual patient waiting time for diagnosis and oncological treatment in Poland, both before and after introducing the oncological reform, and can thus be used to assess how effective such actions undertaken by the Ministry of Health have been.

Our study has shown that the real waiting time for treatment from the suspicion of cancer in Poland was, and is still, too long; in most patients exceeding 9 weeks, with the median time being about 11 weeks both before and after the reform. It should however be stated that when only DILO card data are analysed, as per the NFZ, the analogous median waiting time for the same respondents are 4 weeks; however this data is unreliable as it is solely based on the documentation but does not reflect the actual situation of the patients in reality. There are only a very few studies for determining the actually real waiting time for diagnosing and treating cancer, not only in Poland but elsewhere in the world. These have been attempts to analyze waiting times for diagnosis and treatment of patients suffering from the most common cancers, i.e. lung and breast cancers. A study from 2014 on the causes of delays in treating breast cancer patients ( 260 women from the Lublin region) demonstrated that the average time from the first physician visit to treatment was 3.2 weeks [9]. Another study by Sawicki et al. [10] on 300 patients diagnosed with lung cancer from the Department of Torque-Surgery in Lublin (January 2010 to 2011) showed that the median waiting time for treatment after the first physician visit was 12 weeks. In Finland, diagnosing lung cancer is a priority and treatment is usually given without undue delay. Based on the Finnish database, Salomaa et al. [11] estimated that the median waiting time between starting treatment and the first GP visit was 10.4 weeks in a group of 132 patients diagnosed with lung cancer in 2001. Yorio et al. [12] conducted a retrospective analysis of $482 \mathrm{pa}$ - 


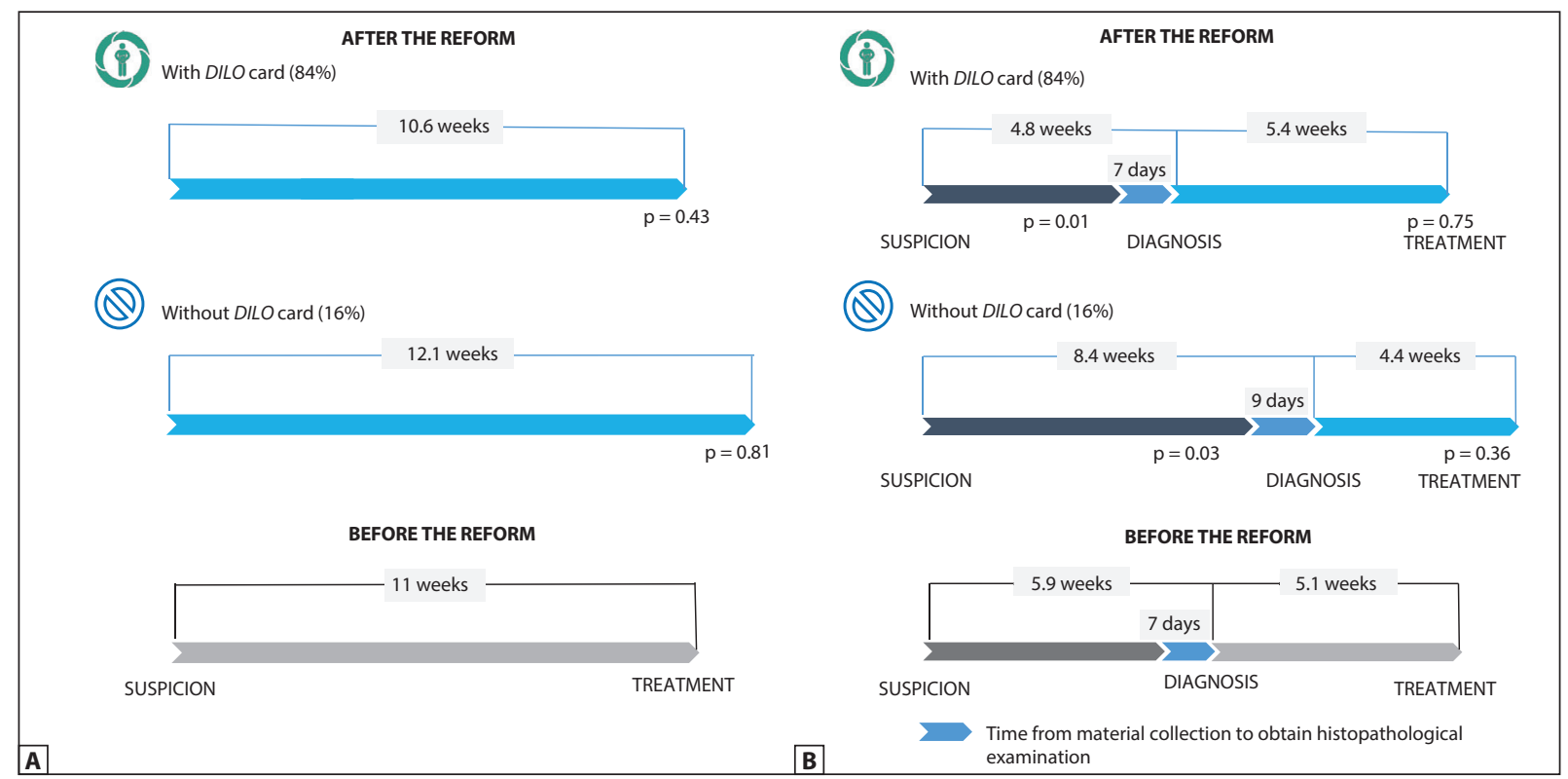

Figure 2. Waiting time (median) between starting treatment and cancer suspicion (A) and waiting time (median) between diagnosis and cancer suspicion along with waiting time between starting treatment and diagnosis (B) before and after introducing the DILO reforms

tients diagnosed with stage I-III non-small cell lung cancer in the United States between 2000 and 2005 and showed an 8.4 week median time between the first imaging test when cancer was suspected to when the treatment started.

Our study has shown that the median waiting time from histopathological diagnosis to suspicion of disease was 5.9 weeks and was decreased by around one week following the introduction of reforms in the DILO card bearing patients, but increased by more than 2 weeks in patients without this card. In Finland, the aforementioned Salomaa et al. [11] study demonstrated that the median waiting time for patients with lung cancer from the first GP visit to diagnosis was 52 days (7.4 weeks). We have shown that the median waiting time between starting treatment from histopathological diagnosis was 5.1 weeks prior to the oncological cancer reform, which remained substantially unchanged after the introduction of the DILO reform. Indeed, this median was similar to the statutory maximum waiting time set in the UK, at 31 days [7].

The aforementioned Yorio et al. [12] study from the USA, showed that the median waiting time between treatment and histopathological confirmation of lung cancer was 33 days. Based on a Canadian database of over 5,000 patients diagnosed with lung, breast and colorectal cancer between 1992 and 2000, the median waiting time to radiotherapy was defined and found to vary according to the type of cancer. In lung cancer, the median time from diagnosis to radiotherapy was 6 weeks, but it was 16 weeks for breast and colorectal cancers [13]. A Dutch study [5] found that the median waiting time of patients with head and neck tumours between histopathological testing to the onset of treatment was 37 days.

Determining the waiting time for oncological treatment is difficult, because defining the date of the first doctor visit when cancer symptoms actually appear is subjective. Also, the retrospective character of this study is linked to the already existing medical documentation of patients, sometimes unfortunately incomplete. Nevertheless, our survey is the largest, in terms of sample size and geographical coverage, of the real waiting time waiting between diagnosis of cancer and oncological treatment as yet undertaken so far in Poland. It also allows statutory public health initiatives to be realistically assessed for their effectiveness. Various studies have proved the likely impact of waiting time on the effectiveness of therapy and thus shortening the waiting time for oncological treatment may turn out to be one of the factors improving survival rates for those patients suffering from cancer in Poland.

\section{Conclusions}

1. The waiting time between treatment and when cancer is suspected in Poland was, and is still too long; in most patients (60\%) this exceeds 9 weeks.

2. Introducing the oncological reform has not significantly reduced waiting times for cancer patients with cancer; a 3 day reduction for those with DILO cards but an 8 day increase for those without.

3. The waiting time reported by the DILO card data does not reflect actual waiting times.

\section{Acknowledgements}

The authors gratefully thank the Oncology Foundation 2025 for organising and funding the study.

Conflicts of interest: none declared 
Karolina Osowiecka, PhD

Department of Radiation Oncology

Hospital of the Ministry of Internal Affairs

with Warmia and Mazury Oncology Center in Olsztyn

Al. Wojska Polskiego 37

10-228 Olsztyn, Poland

e-mail:k.osowiecka86@gmail.com

Received: 2 Mar 2017

Accepted: 26 Jun 2017

\section{References}

1. Wojtyniak B, Goryński P, Moskalewicz B. Sytuacja zdrowotna ludności Polski i jej uwarunkowania. Warszawa: Narodowy Instytut Zdrowia Publicznego - Państwowy Zakład Higieny, 2012: 55-59.

2. KalbarczykWP, Gujski M, Brzozowski S et al. Walka z nowotworami iopieka onkologicznaw Polscewobecwyzwańdemograficznychiepidemiologicznych — propozycjerozwiqzań. Warszawa: Instytut Ochrony Zdrowia, 2015: 14-41.

3. http://eco.iarc.fr/eucan/.

4. De Angelis R, Sant M, Coleman MP et al. Cancer survival in Europe 1999-2007 by country and age: results of EUROCARE-5 — a population-based study. Lancet Oncol 2014; 15: 23-34.
5. van Harten MC, Hoebers FJ, Kross KW et al. Determinants of treatment waiting times for head and neck cancer in the Netherlands and their relation to survival. Oral Oncol 2015; 51: 272-278.

6. Richards MA, Westcombe AM, Love SB et al. Influence of delay on survival in patients with breast cancer: a systematic review. Lancet 1999; 353: 1119-1126.

7. Systemy opieki onkologicznej w wybranych krajach. Raport opracowany przez EY na zlecenie Fundacji Onkologia 2025. Warszawa, 2014.

8. http://www.nfz.gov.pl/dla-swiadczeniodawcy/pakiet-onkologiczny/.

9. Brzozowska A, Duma D, MazurkiewiczT et al. Przyczyny opóźnień leczenia chorych na raka piersi wykrytego $w$ trakcie samobadania u kobiet w województwie lubelskim. Ginekol Pol 2014; 85: 14-17.

10. Sawicki M, Szczyrek M, Krawczyk P et al. Reasons for delay in diagnosis and treatment of lung cancer among patients in Lublin Voivodeship who were consulted in Thoracic Surgery Department. Ann Agric Environ Med 2013; 20: 72-76.

11. Salomaa ER, Sällinen $\mathrm{S}$, Hiekkanen $\mathrm{H}$ et al. Delays in the diagnosis and treatment of lung cancer. Chest 2005; 128: 2282-2288.

12. Yorio JT, Xie $\mathrm{Y}$, Yan J et al. Lung cancer diagnostic and treatment intervals in the United States: a health care disparity? J Thorac Oncol 2009; 4: 1322-1330.

13. Johnston GM, MacGarvie VL, Elliott $D$ et al. Radiotherapy wait times for patients with diagnosis of invasive cancer, 1992-2000. Clin Invest Med 2004; 27: 142-156. 